\title{
Fia Ola: Grief Recovery Following a Tsunami Disaster in Samoa
}

\author{
Byron Malaela Sotiata Seiuli, ${ }^{1}$ Linda Waimarie Nikora, ${ }^{1}$ Ngahuia Te Awekotuku, ${ }^{1}$ and \\ Darrin Hodgetts ${ }^{2}$ \\ ${ }^{1}$ School of Psychology, University of Waikato, Hamilton, New Zealand \\ 2 School of Psychology, Massey University, Auckland, New Zealand
}

\begin{abstract}
$\mathrm{N}$ atural disasters provide humanity with a setting in which to examine core dimensions of life. How people respond to and make sense of their experiences due to the ruptures of trauma and devastation remains vital in grief recovery. An earthquake of 8.3 magnitudes on October 29, 2009 triggered a galulolo (tsunami wave) that devastated parts of Samoa, American Samoa, and Tonga. This calamity provided an ideal setting for a case study examination of how those directly impacted recovered from the devastation. In this article, the experiences of one couple in the context of Samoan grieving processes becomes the key focus. Disaster and grieving literature is examined to inform and provide interpretation to their experiences. It is through such an examination that this article seeks to makes an important contribution to understanding the complexities of loss and culturally patterned responses of Samoan people, like this couple, to disaster recovery.
\end{abstract}

Keywords: galulolo, tsunami disaster, fa'asamoa, trauma and grief recovery, indigenous psychology

On September 29, 2009, an earthquake of magnitude of 8.3 on the Richter scale occurred offshore between Samoa and Tonga at around 6.50 am and lasted for almost 2 minutes (Potoi, Tautua \& Fa'atauva'a-Vavatau, 2000). Though earthquakes occur regularly in this part of the world, this quake was the most fierce many people had ever experienced in their lives. Its tremors were felt not only in Samoa, but also in American Samoa, the northern parts of Tonga, Wallis and Futuna, and as far as Niue (Figure 1).

Following the trembling, many locals proceeded with cleaning up the mess left behind by the massive quake, unbeknown to them that the shakes were only minor compared to the utter devastation that came next - a galulolo (tsunami wave). The Psychosocial Response Report (PSR) that was compiled by members of the Samoa recovery teams situated in Moto'otua reported that it only took 10-15 minutes after the earthquake had stopped for the wave to hit Samoa and Tutuila, at speeds of between 450600 miles per hour, measuring between twenty to thirty feet in height at the worst hit areas' (Potoi et al., 2009, p. 2). In Samoa, the galulolo left 143 people dead in its wake, mostly women, children and the elderly. Five of the victims have never been recovered. Among the deceased were 10 tourists holidaying in Samoa, including some from New Zealand. Over 300 people sustained physical injuries and over 100 were admitted to the Samoa National Health
Services (NHS) situated in Moto'otua, Apia, or satellite clinics in outlying regions. The PSR report also recorded that over 130 surgical procedures were undertaken to aid victims towards physical recovery, not counting those who chose not to report their injuries. The three main districts directly affected were Safata, Falealili, and Aleipata, representing between $37-40$ villages, with a combined population of approximately 5,000 residents.

This article examines Tala and Lelei Tafea's (pseudonyms) traumatic experience of the galulolo, which destroyed their livelihood and personal belongings, and left a gaping hole after four family members were tragically killed. Below, we begin by recounting this family's experience of the disaster, from the galulolo's initial impact, their fight to stay alive, the searching for missing family members, the burial and memorial services to honour their deceased relatives, and finally, their efforts to make sense of and cope with their experiences on a daily basis. We then draw upon insights from Samoan cultural practices and scholarly disaster literature to theorise key issues surrounding the nature of Samoan experience and response to loss and grief in current contexts. A significant objective of this article is to inform readers, particularly helping professionals, who might be called upon to support Samoan individuals and their families affected by trauma. 


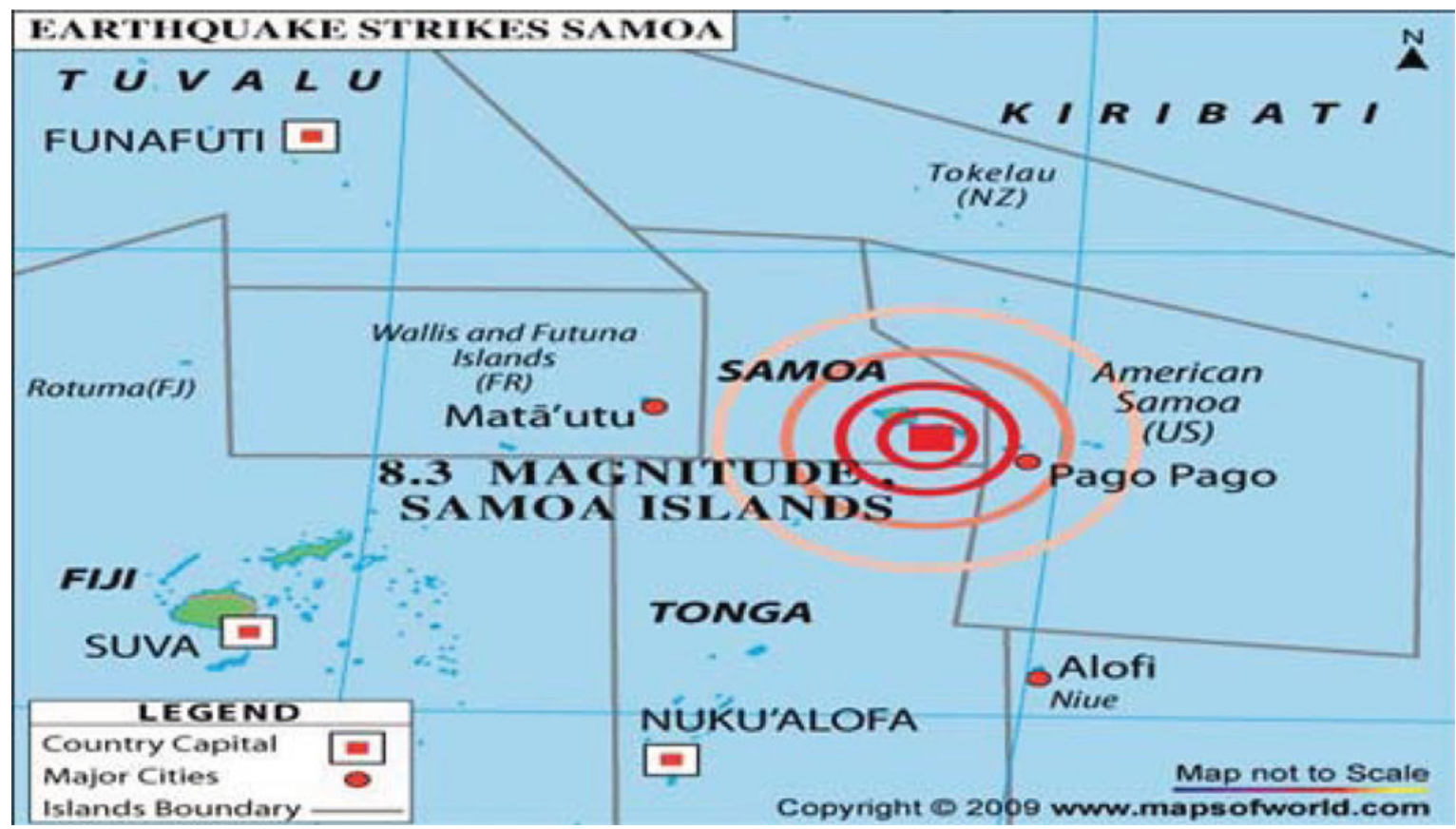

\section{Figure 1}

(Colour online) Mafui'e strikes Samoa.

Note: Sourced with permission from www.mapsofworld.com

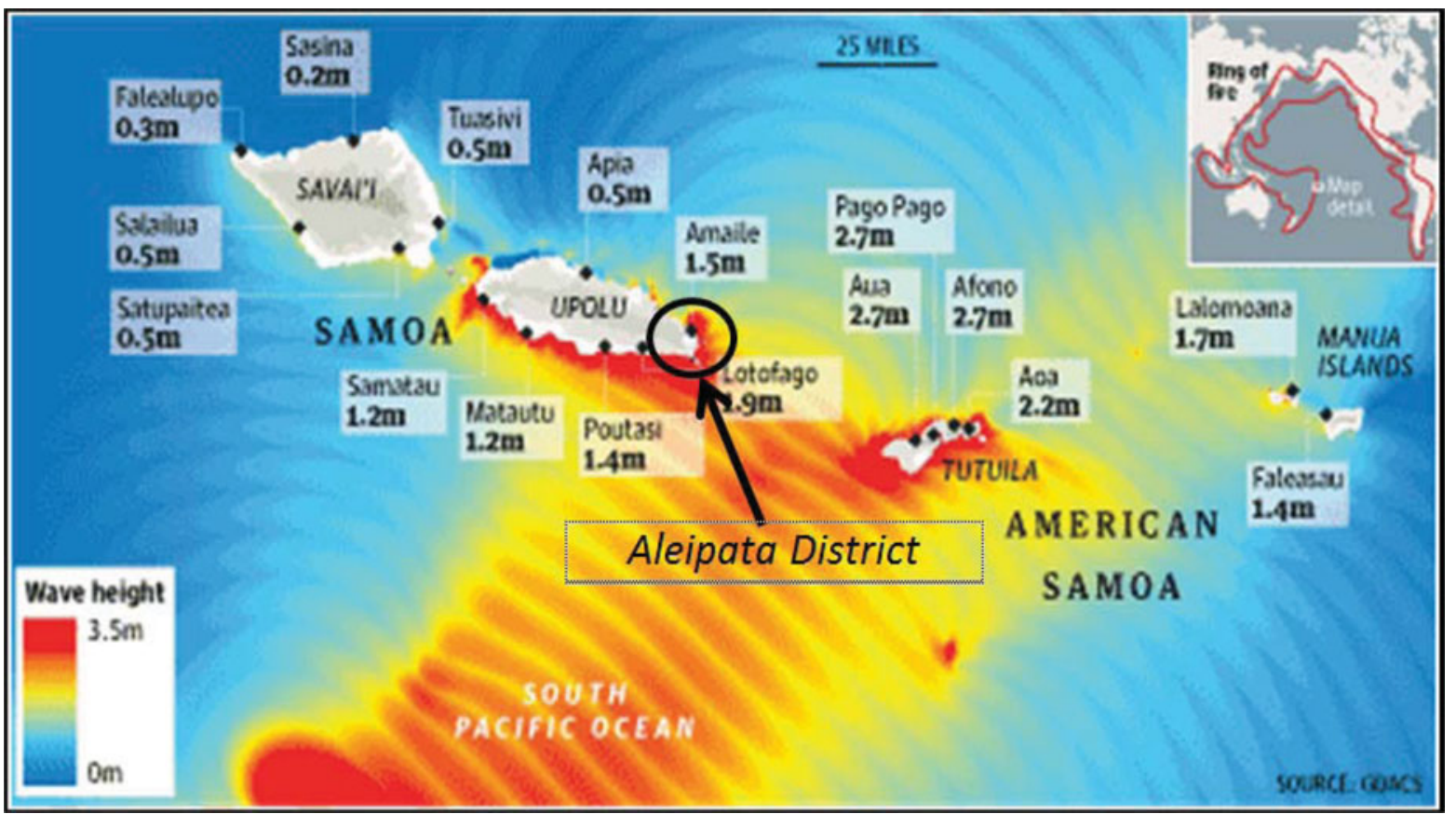

\section{Figure 2}

(Colour online) Galulolo wave on September 29, 2009.

Note: Sourced with permission from http://www.guardian.co.uk/world/2009/

\section{Fia Ola: The Galulolo Devastation and Its Far-Reaching Impact}

After a few years of managing a real estate company in Apia, Tala and Lelei relocated to the coastal district of Aleipata (Figure 2) with their two children, Lau (son) and
Rosa (daughter) to care for Tala's ageing parents. It was while living in Aleipata that they came face to face with the full force of the galulolo. After the earthquake, Tala heard a radio warning reporting that a galulolo wave had hit nearby villages. He scrambled to gather his family to 
head to the hills in their four-wheel drive ute for safety. His wife Lelei frantically grabbed their passport bag and their daughter Rosa. Tala, his father, and their two children headed for the front cab while Lelei jumped onto the deck. Tala's mother was still running towards the ute when the wave reached them.

The wave battered the house first before smashing the ute, flipping it upside-down, crushing Tala's mother under its full weight. Lelei was thrown off the deck and into the ocean, which filled the dry ground they had been standing on just minutes earlier. The force of the wave dragged their upturned vehicle and the helpless Tafea family into the tōga togo (mangroves) swamp next to their house, about a 100 metres inland. The dissipated wave also halted the rolling ute, which now trapped one of Lelei's legs underneath its frame. The pain of her ordeal caused Lelei to become unconscious. Tala was still trapped inside the cab of the ute, battling to stay alive underwater. When he finally broke out and swam to the surface, his gaze fell upon the submerged body of his father, who was dead. Tala tried administering CPR to revive him, but it was to no avail. Tala's mother and his two children were nowhere to be seen.

Lelei had consigned herself to drowning, but as she became conscious, she saw her husband attempting to revive his father. There was also another wave surging through the damaged and depleted shoreline. Tala hoped and prayed that the wave was not as deadly as the first. He swam to embrace his wife, while also holding onto the lifeless body of his father, before they were battered again by the second wave. And the galulolo came back a third and last time. When the wave eventually receded, Tala began the painful task of freeing his wife from under the ute before collecting the ravaged bodies of his family members, starting with his father.

With the help of some village folk, they freed Lelei. Tala moved her and his deceased father to where the debrisstrewn road once was. Much of it was washed away and damaged by the wave. He was then informed that some villagers had found his mother's body. He also placed her by the roadside to await transportation to the nearest hospital before returning to the swamp to search for his missing children. Some time later, he finally discovered the lifeless body of his daughter, Rosa. This discovery caused an overflow of emotion to break loose and he sobbed uncontrollably.

Although fatigued and badly wounded, Tala would not give up his search for his son, Lau. After an agonising search over every bit of the swamp for what seemed like hours, he abandoned the search to transport his daughter's body to the hospital. The journey in the back of a stranger's vehicle while clutching tightly to his baby girl was filled with regrets and haunting memories: his daughter's playfulness, her endearing affection, and her cheerful personality. Tala wished he could somehow exchange places, a longing that would intensify when his son's body was finally found some days after.
Upon reaching the hospital, Tala searched for his wife Lelei, who was now housed in a makeshift tsunami ward with other victims of the galulolo. Lelei was hoping for a miracle, that her children would be found alive. But, as Tala placed Rosa into her trembling arms, Lelei knew that their baby girl was dead. She howled her distress, allowing all her anguish and torment to rupture across the space of the temporary grief-stricken ward, a scene repeated again and again as news of dead relatives was relayed to the injured at Moto'otua Hospital.

Before returning to the swamp to continue in his search, Tala checked the morgue for his son's body. He was not there. Lelei pleaded with God to spare her one child. Despite her earnest plea to the Divine, it was not until three days later that Lau's decomposed body was discovered in the mangroves. At least having a body meant that Tala and Lelei could turn their attention towards organising the burial services for their beloved family members.

\section{Disaster Response and Samoan Funeral Culture}

The scale of the galulolo damage led the Samoan government to offer communal burial sites for deceased victims in a designated government cemetery. For many families affected by the galulolo, the national burial site was located closer to Apia, at least two hours away from the most devastated districts, such as Aleipata. Despite this appealing gesture of support, many families, like the Tafea, chose to bury their relatives on their own family lands and at their own expense. The Tafea family buried their relatives a week after the galulolo; the children first and the parents two days later. The children shared a single coffin while the parents had separate caskets. It was reported that some of the victims who were buried within a short time were wrapped in Samoan mats or body bags, due to the resources and financial wealth being destroyed or compromised by the galulolo. The depleted resources also led some to abandon the usual end-of-life traditions and fa'asamoa (Samoan way) cultural expectations associated with funeral rituals (Seiuli, 2015; Tui Atua, 2009). Instead of regular church funeral services, simple arrangements to honour the dead occurred in spite of pressure to have a more elaborate ritual. For example, Tala's father was both a paramount title holder and lay minister in the Latter Day Saints (LDS) church and was expected to be honoured in an esteemed traditional fashion. But, in this case, there was no family service and the LDS church leaders led a simple funeral service at the burial site to honour this deceased matai (chief).

In mid 2010, Tala and Lelei migrated to New Zealand to access better medical care for Lelei, who underwent numerous operations to save her crushed leg, and also to escape the lingering memory of their devastated environment in the village. Later that same year, the family returned to Samoa to unveil two memorial headstones to commemorate the anniversary of the passing away of 
their family members. The event enabled this couple to find some closure from their prolonged journey of grief, yet they continued to struggle with the pain of their multiple losses. Intense guilt continued to surface as a reminder to Tala in particular, that he was alive and his parents and children were dead. He continued to battle with the belief that he did not do enough to save them. Despite these intrusions, this couple are doing their best to journey forward with a space once occupied by the lived presence of Lau, Rosa and Tala's parents, one full of life, joy, memories, laughter, opportunities, and dreams. The galulolo ripped their lives apart in a matter of moments and it has never been the same since.

\section{Interpretation of These Events}

Environmental calamities like the galulolo are unexpected; they occur suddenly with overwhelming devastation and long-term effect (Figley, 1985; Tedeschi \& Calhoun, 1995). The speed at which the waves swept up to the Tafea family's doorsteps left them defenceless to its devastating onslaught, causing social disruption, loss and damage to property, and mass causalities. A galulolo is different from other life events because they manifest in 'extreme or sudden force, typically causing fear, anxiety, withdrawal, and avoidance' (Ursano, Fullerton, \& McCaughey, 1994, p. 5). While the initial event might last moments or minutes, the bodily injury and emotional shock can persist for weeks, months, or many years after. This is often complicated when multiple causalities are also experienced first hand by those with little or no prior experience.

Tala referred to his emotional state immediately after the galulolo struck as 'mechanical', helping him to respond bravely to keep his wife alive, and then to search for the missing bodies of his family. Malt (1994) suggests that this period is generally referred to as 'emotional shock, denial, or numbness phase' (p. 106), one that often determines the way people respond when in life threatening situations. This initial response is often interpreted as 'victims experience strong anxiety, without loss of behavioural control' (Malt, 1994, p. 106). Tala's emotional experiences mirror this phase, where he had mentally shut out those raw emotions associated with the destruction, choosing instead to maintain a sense of calmness and of being in control to save and to find his missing family members. They remained the priority. Hodgkinson and Stewart (1998) suggest that being in a state of shock is a 'defensive manoeuvre' (p. 7) that assists survivors to disengage from the catastrophic reality. The conclusion often associated with survivors expressing these symptoms is that they are 'in control and coping bravely' (Hodgkinson \& Stewart, 1998, p. 7) when, in fact, they have not yet begun to react to the calamity.

Responding to a galulolo often means encountering the injured and the dead in devastation unlike other events (Sawrey, Waldegrave, Tamasese, \& Bush, 2011; Ursano \& McCarroll, 1994). This was certainly experienced by Tala and Lelei, and many others affected in Samoa, American Samoa, and Tonga. While trauma and disasters and their related devastation are frequent global occurrences, this does not necessarily mean people are prepared for such a first-hand experience. Exposure to individual and mass death can be disturbing and frightening, often embedding lasting impressions psychologically, especially when the deaths are of people with whom there are meaningful connections or close emotional bonds (DeRanieri, Clements, \& Henry, 2002; O'Connor, Johnston, \& Evans; 2011). The tasks of body recovery, identification, transport, and burial of the victims can prolong contact with the realm of the dead. Such acute experiences can significantly contribute to the development of psychological distresses that delay recovery for those affected, resulting in shock, fear and anxiety - before, during, and after the trauma (Holloway \& Fullerton, 1994).

\section{Aitu: Uncovering Samoan Mourning Rituals}

In traditional Samoa, Turner (1984) reported that unfound and unburied bodies aroused great concern for a grieving family: the spirit of an unretrieved body belonging to a family member killed in war or drowned was regarded as left to 'wander about, neglected and comfortless' (Turner, 1984, p. 150). The 'unburied' do not rest in peace but drift restlessly and vengefully. Until a body is recovered, there is a belief that the spirit or ghost of the dead will continue to haunt the family night and day, with the wandering spirit calling continually from the realm of the dead, urging the family to bring them home (Hodgkinson \& Stewart, 1998). Such spirits often manifest themselves in dreadful cries as they search restlessly, seeking to cling to and to press people down. Worse still, the disenchanted spirit can affect the living with sickness and disease (Hodgkinson \& Stewart, 1998, Stair, 1983; Turner, 1984). As a result, resting or sleeping may not come easily to family members until the relative's body is laid to rest. But first they must be found.

It was Tala and Lelei's mission to find and retrieve their missing son Lau - a spiritual duty in some way because all that they could see and hear was their son running around in the mangroves, trapped and desperate to be reunited with them. Tala says about this experience: 'I kept seeing him in the mangroves, calling "Mummy, Daddy, where are you?"' It is for this reason that some survivors in Samoa scrambled to quickly identify deceased bodies and, in some instances, families prematurely identified bodies that were, in fact, not their relatives. This was particularly evident with infants or young children whose features or clothing was beyond recognition. One family revealed during an interview that an infant belonging to them was buried in someone else's burial plot because the child was incorrectly identified by the family who discovered the body immediately after the devastation. For others, repeated visits to the hospital were needed because 
relatives refused to believe or accept that the dead person actually belonged to their family. To have a body conveys a peculiar comfort that permits a family to say farewell to their loved one. Burial therefore presents some form of closure for those who remain, a reassurance in some way that their deceased family member will be unified with ancestors in the family tu'ugamau (resting place).

Many in the Samoan community, like the Tafea family, recognise that with a death, the general mourning rituals will include: important family fono (gathering) to consolidate resources; memorial church services; transferring the body home; receiving donations from visitors; and reciprocating honour to all who come to offer support (Ablon, 1971; Seiuli, 2015). These rituals represent significant markers in Samoan mourning traditions, thus providing a helpful path to transition mourners through the various cultural and religious rituals involved. They also signal a beginning and end point for cultural and religious rituals. Under normal circumstances, end-of-life decision-making lies in the domain of traditional leadership, where the $s a^{\prime} o$ (appointed family head) and those matai (leaders) with designated authority provide family governance (Seiuli, 2013, 2015). During these times, the collective unit's effort is to ensure that the deceased person is farewelled appropriately and according to their status (Tamasese et al., 1997; Turner, 1984). The manner by which the deceased person is farewelled directly relates to the family's ability to perform their duties correctly. For some, funeral services that are performed with extravagance and generosity become the measuring stick for expressing their love to their deceased relative. Despite their harrowing ordeal and trauma, Tala and Lelei were expected by some of their àiga (kin members or extended relational ties) to still provide an elaborate cultural funeral for their deceased parents. This was deemed important because of Tala's father's status as a Samoan chief and retired minister. After various family fono (discussions) that included Tala and Lelei, the family chose to enact simpler funeral services for their deceased members.

Funeral preparation, whether in Samoa, New Zealand or other places, usually begins after the pronouncement of death. Matai (appointed family chief), close bilateral kin, and older respected relatives' fono (assemble) to make the practical decisions for burial arrangements, and for religious services (Ablon, 1970). Aside from various fono to gather and combine resources, preparation also means arranging space in the family home as a liminal falelauasi (mourning house) for the deceased to lie in state. Various temporary shelters are erected for food preparation and other general duties. The family garage is converted into a meeting house and storage facility for si'ialofa (gifted items) that are donated by visiting delegations, and any additional resources collected by the family themselves. In urban settings, those who rally to support a family in crisis are not limited to one's extended relations, but embrace others associated with the deceased through their workplace, church, sporting clubs, and from other settings. Ablon (1971) suggests that relatives or close family friends will make an effort to visit the deceased at his or her house to make their presentation and offer consolation to the family.

The practice of fa'aaloaloga fa'asamoa (reciprocated gifting) is a significant process within death and mourning occasions for many Samoan people. In such contexts, it is essential that one must be seen to reciprocate with those who support one's 'àiga (extended family) in their times of need. Embree (1933) observed this practice in a village in Tutuila and commented that 'exchange is the very essence not only of courtesy but of self-respect' among Samoans (p. 566). To withhold the exchange or to be denied the opportunity to express themselves in the form of reciprocated exchange was, in effect, to 'seize their souls' (Embree, 1933, p. 566). What Embree is suggesting is that the ritualised practices of si' ialofa and the counter exchange of sua (tributary meal) and meaalofa (financial gifts) speaks to the heart and soul of fa'asamoa traditions. Such heartfelt exchanges are motivated by aga'alofa (compassion) that reflects Christian and community compassion (Sawrey et al., 2011). It is on the basis of such devotion that one might view the desire of the extended Tafea family for more appropriate performance of Samoan funeral culture symbolic of the father's status.

Nevertheless, the acknowledgment and inclusion of these important cultural patterns remains imperative to Samoan identity and belonging (Tamasese et al., 1997; Tui Atua, 2009). In this regard, many Samoan people's participation in funeral customs not only helps them to actively engage with the event itself, but also allows them to respond to the challenge of embracing the cultural patterns of old that have been passed down through the generations. Funeral customs materialise history and culturally patterned relationships by keeping them alive and evolving through their continuous enactment (Stolte \& Hodgetts, 2013; Seiuli, 2015). For many Samoans, active engagement in funeral rituals assists them to transfer these cultural ideals into a living identity to validate their Samoan heritage (Seiuli, 2004, 2013), one that is worthy of being embraced and passed on to future generations.

This catastrophe caused the majority of Samoans in Samoa and other places to gather in a time of collective mourning. For those affected by this tragedy, it relegated the responsibility for funeral rituals and preparations to those available or surviving family members to perform for themselves (Tui Atua, 2009). How end-of-life rituals were enacted in the context created by the galulolo was a forced departure from regular Samoan funeral traditions already discussed in this article. As highlighted in the case presented, the Tafea family were caught in the death process absolutely. Those survivors, Tala and Lelei, honoured their loved ones as best they could given their circumstances and the fact of progressing decomposition. Their loved ones had to be laid to rest, and they were.

The galulolo greatly depleted family resources, which affected the way Tala and Lelei were able to provide burials 
for their family members. Significantly, their own injuries sustained during the wave and the emotional pain they experienced from losing four family members in one event remained a constant reminder of their brush with death. The devastation of this calamity forced many in Samoa to re-examine the core values associated with contemporary funeral culture. Few, if any, of the funerals following the galulolo reflected the traditional and usual pageantry and ritual performance associated with such occasions (Tui Atua, 2009). Notably, Tui Atua (2009) reported observing post-galulolo that funerals became very simple affairs because people became preoccupied with the priority of caring for the injured and sorting through the destruction within their community. During this grieving period, the decaying bodies not only dictated the speed with which funerals were performed, but equally significant were the limited resources. These funeral services were completed quickly and without too much elaboration. Similarly, the funerals for both Tala's parents and his children were completed in a simple fashion, keeping financial costs to a minimum.

\section{Journeying With Grief}

Through the trauma created by the galulolo, which remains for many an ongoing presence and challenge, one might ask: Has any good arisen? Disruption presents an opportunity for people to enact their reflective and reflexive capacities. The galulolo created an ideal context for reassessing the value of life and its performance, and the opportunity to do things differently. In some instances, Samoan funeral culture has been the target of fierce criticism and discussion because of the perceived exploitation and greed among those who seek to benefit from these difficult times (Tui Atua, 2009, 2011). The issue of available resources remains important to the way funeral rituals are carried out, not only in normal circumstances, but especially when many of these resources are damaged by a catastrophic event such as the galulolo. More discussion is required on this topic, particularly if those end-of-life cultural rituals are to be celebrated as life giving and life affirming.

Although there is a growing concern over the increasing costs of maintaining Samoan funeral patterns, many have shown that they can take care of their responsibilities by pooling their resources together (Ablon, 1970, 1971; Braginsky, 2003; Seiuli, 2015). A Samoan proverb reiterates this notion of communal support where it declares: 'A e iloa a'u i Togamau, ou te iloa foi oe i Siulepa', which means 'if you do me a good deed in Togamau, I will reciprocate in Siulepa' (Tui Atua, 2009, p. 5). Community support and the reciprocal performance of fa'asamoa customs is motivated by the knowledge that the kindness will be reciprocated at some point in time. For some, there is a prescribed expectation to offer help to other family members as a way of showing respect (Ablon, 1970). Ablon (1970) further suggests that the strength of such vital connections supports many Samoan communities to better handle death and grief processes than the Palagi $(\mathrm{Eu}-$ ropean) population in general, helping to alleviate some of the emotional distress characteristically associated with bereavement.

How individuals and communities prepare for, behave during, and respond after witnessing a traumatic death often determines their ability to cope with the aftermath of such a crisis (Ursano \& McCarroll, 1994). Psychological responses to tragic events underlie 'the reactions of normal human beings to sudden, unexpected and terrifying events in their lives' (Hodgkinson \& Stewart, 1998, p. 1). Such reactions can form the basis for surviving, attempting to cope, trying to recreate a meaningful existence, and of finding the will to move on. Mooney and colleagues (2011) argue that 'recovery is [not] a simple process' (p. 27), and may not necessarily mean a return to life pre-disaster. Nevertheless, steps towards recovery need to happen in spite of the recall of memories that linger every day and everywhere. It involves some form of progression, from the event and its aftermath, towards a process of transformation and renewal (Bowlby, 1980; Kubler-Ross, 1969; Levang, 1998; Rando, 1995).

Survivors of such profound devastation often seek to process the 'why' questions associated with their survival: Why me? Why is it that they died and not me? Why did God cause this to happen to our family? In addition to these questions are the reported feelings of guilt about whether their actions or lack of action could have made a difference to those who passed away in the calamity (Hodgkinson \& Stewart, 1998). Considering Tala and Lelei's situation as survivors of the galulolo, their feelings of guilt were initially felt intensely because they survived while their children and Tala's parents all died. Understandably, this couple avoid talking about the events of the galulolo because it invokes too many painful memories. An imprint of death caused by the calamity continues to provide haunting images of the Tafea's encounter with the galulolo. The result of 'cumulative effects of several losses and the virtual eradication of social support networks' (Hodgkinson \& Stewart, 1998, p. 40) left Tala and Lelei feeling totally alone in their grief.

The death of children elicits more intense and complex grief reactions for surviving parents than other types of bereavement (Wijngaards-de Meij et al., 2008). For Tala and Lelei, losing both of their children severely affected and completely disrupted them as parents. Wijngaards-de Meij and colleagues suggest that the heightened sense of loss experienced is related to both parents being in grief simultaneously and therefore neither being able or available to support the other. This couple's inability to support the other person only intensified the grief process they felt. Tala admitted that their combined grief caused him to become clinically depressed, affecting his mind and body. The worst moments were characterised by 'whole body grief, where the aching remains ever present and accompanied by flowing tears, sorrow, pain, and depression. 
Tala's grief was not only experienced through his physical, social and emotional being, but also affected him spiritually; that is, his 'soul' was also ripped apart with the excruciating pain of their loss.

Tala and Lelei's decision to relocate to Auckland, New Zealand from Aleipata in mid 2010, where family and village support were closely available, precipitated an increase in the levels of depression, loneliness, and isolation they reported experiencing. Tala suffered from insomnia and was referred to a local general practitioner for treatment, who then prescribed him medication to alleviate his levels of anxiety and sleeplessness. Tala did not take the medication. He refused to allow his grief to be numbed involuntarily, because the pain of losing his parents and kids reminded him of the place they once occupied in his life. Tala and Lelei were later referred to a Pacific clinician for trauma counselling and support. Using Pacific models of engagement, the clinician was able to help this couple to reconnect with their cultural identity to make sense of their losses. Importantly, they received counselling support to address their own trauma recovery. Shortly after the start of these therapeutic sessions, Tala found parttime employment with a Pacific healthcare agency who were engaged in the Like Minds, Like Mine campaign aimed at reducing discrimination and stigma associated with mental health illness. Tala's employment as an educational facilitator provided a pathway to share his story of trauma and grief with his audience, and his efforts to overcome depression and anxiety resulting from his loss. Retelling his story of survival allowed Tala to release some of his inner turmoil slowly with those who were also suffering from various anxieties like his. Importantly, he discovered that a vital part of his recovery came through the opportunities to help others through their grief, thus indirectly providing a way of helping himself.

For Tala and Lelei, one way to manage their emotional pain was to keep the memories of their loss to themselves. Private memorialisation and incremental steps were the preferred ways to move towards regaining regular routines. While aspects of their grief remained private, their process of healing was not. As discussed earlier in this article, the level of support available through family and church community helps to transition many Samoan mourners through the initial period of grieving (Sawrey et al., 2011; Tamasese et al., 2007). This level of support continues to be an integral part of Tala and Lelei's recovery journey. Moreover, the strength of their love and support for each other in perilous times illustrated again the depth of their marital bond, their faith in God, and their undivided commitment to their family. They battled the galulolo waves together, and now they needed to battle depression, fatigue, loneliness, memory triggers, and grieving tears, side by side.

Since moving to New Zealand, Tala and Lelei have been blessed with three more children: two boys and a girl. They attribute these new additions to God blessing them for the way they served Tala's parents while alive. Though a vacuum was left by the death of four family members, they believe that their three healthy children are God's meaalofa (gift) through their recovery. The children remain core to their healing and restoration. Their recovery journey so far demonstrates an undeniable sense of resilience and purpose that is grounded in their Christian faith, affirming and carrying them through. This way of dealing with death concurs with what Ablon (1970) reported, that despite painful events of whatever magnitude, for many Samoan people, 'life must go on'. Tala and Lelei have demonstrated this life journey of recovery as one of purpose and spiritual faith, and an unbreakable love and respect for each other.

\section{Methodology}

The case presented in this article forms part of a larger doctoral study at the University of Waikato on Samoan grieving practices conducted in New Zealand, Samoa, and California. The research documented the processes by which Samoan people, especially men, coped with death impacts. Narrative inquiry was considered the most appropriate qualitative approach to engage Samoan participants as they storied their lives through death and bereavement experiences. Engaging participants using this research method enabled them to explore meanings to such challenging life events (Ballard, 2009; Buckle, Dwyer, \& Jackson, 2009; Ellis \& Bochner, 2000). This approach is deemed to be particularly useful where there is a scarcity of information that considers the experiences and difficulties faced by a particular population (Hancock \& Algozzine, 2006), which is the case for Samoan death and bereavement paradigms.

The uniqueness and centrality of Samoan cultural protocols being vital to the methodological approach was also an important consideration. Themes, practices and approaches common to Samoan people's ways of life were acknowledged and validated (Seiuli, 2010, 2013; Vaioleti, 2006); for example, important protocols of attending to and maintaining appropriate relationship boundaries (tua'oi) with recognised community leaders such as matai (chief), ministers, elders, and respondents of the opposite gender. It is also significant and culturally imperative to attend to these when discussing subjects with sanctioned parameters such as the death of a family member. Taking care to be mindful of these cultural protocols reinforces the $v a$ fealoaloa' $i$ (relational space), the role of fa'aaloalo (respectfulness), and the values of agaga fesoasoani (collaboration; Seiuli, 2015; Tamasese, Peteru, \& Waldegrave, 1997). These values served to underpin the philosophical direction and focus of the research.

The outcome of this culturally compatible approach is that the data gathered became grounded in first-hand experiences, resulting in deeper insights into the meaningmaking processes involved with death impacts. This process is a reflection that lives are not static, fixed in place, but ceaselessly in the process of many journeys from one place to another' (Knowles, 2000, p. 217). This 
way of examining the lives of Samoan people is another chapter of their malaga (journey), both in their diaspora from Samoa, and their developing identity as New Zealanders.

\section{Empirical Engagements and Analysis}

For the study, a total of 22 participants (19 men and 3 women) were interviewed who identified themselves as Samoans and were aged 18 years and above. Of the 22 participants, 5 lived in Samoa, 4 in California in the United States, and 13 in New Zealand. The fono fa'atalatalanoa (narrative dialogue) involved an examination and documentation of important areas in each of the participant's life, such as their family history and connections to Samoa, their aiga (family) relational networks, their specific involvement in traditional or contemporary family rituals, their spiritual practices, and their pathways of coping when a death affects their family.

All of the recorded interviews were transcribed verbatim, thus providing written accounts of what the respondents said. The interview transcripts were then reorganised under key questions explored in the talanoa interview schedule, which allowed for participants' responses to be categorised and organised. Field notes were analysed in conjunction with the interview transcripts, and coded according to the relevant categories or themes. The outcome of this process resulted in the writing and analysis becoming closely connected with many of the themes and findings emerging through the writing process. Thematic analysis is a common technique used to support a narrative analysis, thereby extending the focus of the analysis beyond the mere content of the narratives, and considers the wider aspects of significant action and events within the narrative (Riessman, 2008). Like the case study presented in this article, the fono fa'atalatalanoa followed both a descriptive and exploratory pathway that enabled a deeper understanding of the how and why questions within the context of death rituals and mourning customs from these Samoan individuals and their families (Yin, 2012).

\section{Concluding Thoughts}

Samoan grief resolution processes, such as those examined through Tala and Lelei's account, encompass not only the physical, social and psychological dimensions of their humanity, but also connect these to their spiritual faith, their family networks, and their cultural heritage. While death itself is an unpredictable event, associated cultural and religious rituals are generally familiar for many Samoans in mourning. As this case has demonstrated, it is within such moments of unpredictable disruption that lives are punctuated by familiar rituals that are meaningful and helpful. The ordinariness of such occasions conducted across a 'landscape of despair' provides 'spaces for care' so that Samoan families like the Tafea family find support and healing in their acts of service (Stolte \& Hodgetts, 2013).
The journey of returning to normal life patterns embraces the need to create spaces of care brought upon by despair of severed relationships by death. In the context of Samoan funeral patterns, it does this by recognising the importance of Samoan cultural rituals and adhering to values to facilitate avenues of healing for those in grief.

A key point highlighted by this case is how the Tafea family had to contend with their own survival while also having to deal with the emotional and psychological impact of losing people of two generations close to them. Because of this way of experiencing death, Tala and Lelei had to enact simpler ways of burying their deceased relatives due to the lack of resources and the important issue of decomposing bodies. The specific situation faced by this couple not only left them to deal with the traumatic aftermath of their personal ordeal, but to find cultural and religious pathways to memorialise their loved ones despite their own need for support. And although the galulolo ravaged their lives, it could not rescind the vital role of family support and of religious faith to assist these grievers in their physical, emotional and psychological recovery.

\section{References}

Ablon, J. (1970). The Samoan funeral in urban America. Ethnology, 9, 209-227.

Ablon, J. (1971). Bereavement in a Samoan community. British Journal of Medical Psychology, 44, 329-337.

Ballard, R. (2009). Grandpa's call: Conscience, ethics, and aporias. Qualitative Inquiry, 15, 467-482.

Buckle, J., Dwyer, S.C., \& Jackson, M. (2009). Qualitative bereavement research: Incongruity between the perspectives of participants and research ethics boards. International Journal of Social Research Methodology, 13, 111-125.

Bowlby, J. (1980). Attachment and loss: Vol. 3. Loss: Sadness and depression. London: Hogarth.

Braginsky, R. (2003). Balanced reciprocity: Ceremonial exchange practices during a Samoan funeral. Horizon, Hawaii: Kapiolani Community College. Retrieved from http://bosp.kcc. hawaii.edu/Horizons/Horizons2003/Balanced_Reciprocity. html

DeRanieri, J., Clements, P., \& Henry, G. (2002). When catastrophe happens: Assessment and intervention after sudden traumatic death. Journal of Psychosocial Nursing \& Mental Health Services, 40, 30-43.

Ellis, C., \& Bochner, A. (2000). Autoethnography, personal narrative, reflectivity: Research as subject. In N. Denzin \& Y. Lincoln (Eds.), Handbook of qualitative research (2nd ed.). Thousand Oaks, CA: Sage.

Embree, E.R. (1933). Samoa offers an exchange. Social Forces, 11, 559-569. Retrieved from http://www.jstor.org/stable/ 2570283

Figley, C. (Ed.). (1985). Trauma and its wake: The study and treatment of post-traumatic stress disorder. Bristol, PA: Brunner \& Mazel. 
Hancock, D.R., \& Algozzine, R. (2006). Doing case study research: a practical guide for beginning researchers. New York: Teachers College Press.

Hodgkinson, P., \& Stewart, M. (1998). Coping with catastrophe: A handbook of post-disaster psychosocial aftercare (2nd ed.). London: Routledge.

Holloway, H., \& Fullerton, C. (1994). The psychology of terror and its aftermath. In R. Ursano, B. McCaughey, \& C. Fullerton (Eds.), Individual and community responses to trauma and disaster: The structure of human chaos (pp. 31-45). New York: Cambridge University Press.

Knowles, C. (2000). Burger King, Dunkin Donuts and community mental health care. Health \& Place, 6, 213224.

Kubler-Ross, E. (1969). On death and dying. New York: Scribner Classics.

Levang, E. (1998). When men grieve: Why men grieve differently and how you can help. Minneapolis, MN: Fairview Press.

Malt, U. (1994). Traumatic effects of accidents. In R. Ursano, B. McCaughey, \& C. Fullerton (Eds.), Individual and community responses to trauma and disaster: The structure of human chaos. New York: Cambridge University Press.

Mooney, M., Paton, D., de Terte, I., Johal, S., Karanci, A., Gardner, D., ... Johnston, D. (2011). Psychosocial recovery from disaster: A framework informed by evidence. New Zealand Journal of Psychology, 40, 26-38.

O'Connor, F., Johnston, D., \& Evans, I. (2011) The context in which we examine disaster in New Zealand: An editorial. New Zealand Journal of Psychology, 40, 2-6.

Potoi, N., Tautua, P., \& Fa'atauva'a-Vavatau, R. (2009). Psycho Social Response Team report. Apia, Samoa: Ministry of Health, Samoa.

Rando, T. (1995). Grief and mourning: Accommodations to loss. In H. Wass \& R. Neimeyer (Eds.), Dying: Facing the facts. Washington, DC: Taylor \& Francis.

Riessman, C. (2008). Narrative methods for the human sciences. Los Angeles: Sage Publications.

Sawrey, R., Waldegrave, C., Tamasese, K.T., \& Bush, A. (2011). After the earthquakes: Immediate Post-disaster work with children and families. New Zealand Journal of Psychology, 40, $58-63$.

Seiuli, B. (2004). Meaalofa: A gift handed over. Making visible and accessible Samoan counselling in New Zealand (Masters thesis). University of Waikato, Hamilton, New Zealand.

Seiuli, B. (2010). Meaalofa: Making visible Samoan counselling in New Zealand. New Zealand Journal of Counselling, 30, $47-63$.

Seiuli, B. (2013). Counselling psychology from a Samoan perspective. New Zealand Journal of Psychology, 42, 42-50.
Seiuli, B. (2015). Ua tafea le tau'ofe: Samoan cultural rituals through death and bereavement experiences (doctoral thesis). University of Waikato, Hamilton, New Zealand.

Stair, J.B. (1983). Old Samoa or flotsam and jetsam from the Pacific Ocean. Papakura, Auckland: R McMillian.

Stolte, O., \& Hodgetts, D. (2013). Being healthy in unhealthy places: health tactics in a homeless lifeworld. Journal of Health Psychology, 20, 144-153. doi:10.1177/1359105313500246

Tamasese, K., Peteru, C., \& Waldegrave, C. (1997). Ole taeao afua: The new morning: A qualitative investigation into Samoan perspectives on mental health and culturally appropriate services: A research project carried out by The Family Centre. Lower Hutt, Wellington: The Family Centre.

Tedeschi, R., \& Calhoun, L. (1995). Trauma and transformation: Growing in the aftermath of suffering. London: Sage Publications.

Tui Atua, T.T.T.E. (2009, November). O le e lave i tiga, ole ivi, le toto, ma le aano: He who rallies in my hour of need is my kin. Paper presented at the NZ Families Commission Pasifika Families' Fono, Auckland, New Zealand.

Tui Atua, T.T.T. (2011, February). E le o se timu na to, o le ua e afua mai i Manua: A message of love from fanauga. Paper presented at the James Ritchie Memorial Symposium, University of Waikato, Hamilton, New Zealand.

Turner, G. (1984). Samoa: A hundred years ago and long before. Apia, Samoa: Commercial Printers Ltd.

Ursano, R., \& Fullerton, C. (1990). Cognitive and behavioral responses to trauma. Journal of Applied Social Psychology, 20, $1766-1775$.

Ursano, R., Fullerton, C., \& McCaughey, B. (1994). Trauma and disaster. In R. Ursano, C. Fullerton, \& B. McCaughey (Eds.), Individual and community responses to trauma and disaster: The structure of human chaos (pp. 3-30). New York: University of Cambridge Press.

Ursano, R., \& McCarroll, E. (1994). Exposure to traumatic death: The nature of stressor. In R. Ursano, B. McCaughey, \& C. Fullerton (Eds.), Individual and community responses to trauma and disaster: The structure of human chaos (pp. 4671). New York: Cambridge University Press.

Vaioleti, T. (2006). Talanoa research methodology: A developing position on Pacific Research. Waikato Journal of Education, $12,21-34$

Wijngaards-de Meij, L., Stroebe, M., Schut, H., Stroebe, W., van den Bout, J., \& van de Heijden, P. (2008). Parents grieving the loss of their child: Interdependence in coping. British Journal of Medical Psychology, 47, 31-42.

Yin, R. (Ed.). (2012). Applications of case study research. Thousand Oaks, CA: Sage Publications. 